\title{
Bacterial Community Diversity of Fermented Pepper in Brazzaville Revealed by Illumina Miseq of 16S rRNA Gene
}

\author{
Angélique Espérance Lembella Boumba1,2, Augustin Aimé Lebonguy², \\ Joseph Goma-Tchimbakala1,2*, Stech Anomene Eckzehel Nzaou', \\ Chancelvie Pahivelle Limingi Polo1, Mickaëlle Bokamba Moukala1,3 \\ ${ }^{1}$ Institut National de Recherche en Sciences Exactes et Naturelles, Brazzaville République du Congo \\ ${ }^{2}$ Ecole Nationale Supérieure d'Agronomie et de Foresterie, Brazzaville République du Congo \\ ${ }^{3}$ Faculté des Sciences et Techniques, Brazzaville, République du Congo \\ Email: ^goma.tchimbakala@gmail.com, esplembs@gmail.com, lebonguyaa @gmail.com, stechanomen@gmail.com, \\ liminguipolo@gmail.com, b.mickaelle@gmail.com
}

How to cite this paper: Boumba, A.E.L. Lebonguy, A.A., Goma-Tchimbakala, J., Nzaou, S.A.E., Polo, C.P.L. and Moukala, M.B. (2021) Bacterial Community Diversity of Fermented Pepper in Brazzaville Revealed by Illumina Miseq of $16 \mathrm{~S}$ rRNA Gene. Food and Nutrition Sciences, 12, 37-53.

https://doi.org/10.4236/fns.2021.121004

Received: November 13, 2020

Accepted: January 25, 2021

Published: January 28, 2021

Copyright ( 2021 by author(s) and Scientific Research Publishing Inc. This work is licensed under the Creative Commons Attribution International License (CC BY 4.0).

http://creativecommons.org/licenses/by/4.0/

\section{(c) (i) Open Access}

\begin{abstract}
Fermented foods play an important role in the daily life and diet of the populations in Congo. Among these fermented foods, there is Pilipili or fermented pepper which is consumed without prior cooking. The microorganisms present are eaten alive. Few studies have been carried out on these microorganisms which may have beneficial effects on health. This study aimed to investing taxonomic diversity of bacterial communities in 3 samples of fermented peppers produced in 3 distinct areas of Brazzaville. To do this investigation, Illumina Miseq sequencing of $16 \mathrm{~S}$ rRNA gene was used. The results showed that the number of identified operational taxonomic units (OTUs) ranged from 156 to 392. All OTUs belong to the domain of Bacteria and could be categorized into 21 Phyla, 36 Classes, 58 Orders, 100 Families and 171 genera. Firmicutes and Proteobacteria were the main dominant phyla of the total phyla present with a relative abundance of $89.12 \%$ and $8.08 \%$, respectly. At the class level, Bacili were dominant in EB1 (99.50\%), EB3 (85.32\%) and EB2 (42.29\%) while Clostridia in EB2 (40.10\%). Lactobacillus, Clostridium sensu stricto and Frutobacillus were the dominant genera in the sample EB1, EB2 and EB3, respectively. The hierarchical classification showed that the samples EB1 and EB2 form the same group and EB3 is unique. Principal component analysis showed that the younger EB3 and EB2 samples were more diverse than the older EB1 sample. This study is a first in Congo on the diversity of fermented pepper using Illumina Miseq. It has shown that this food is very diverse and can be a source for the isolation of bacteria with biotechnological potential.
\end{abstract}




\section{Keywords}

Illumina Miseq, Diversity, Bacteria, Fermented Pepper

\section{Introduction}

Pepper is a plant belonging to the Capsicum genus of the Solanaceae family [1] [2]. It includes several species including Capsicum annuum, $C$. frutescens, $C$. baccatum, C. pubescens and C. chinense [2] [3]. Pepper fruits are highly prized around the world and are used in seasoning dishes. They are eaten fresh, fried, powdered, as a canned fermented puree [3] [4] [5]. For the preparation of fermented pepper, the fruits are washed with water and crushed. The puree obtained is placed in a flask or jar which is subsequently closed and left to ferment at room temperature. It should be noted that depending on the producers, oil and/or salt are added to extend the shelf life.

Peppers, like other traditional fermented foods, are generally prepared under non-standardized conditions, which lead to variability in the final product [6]. This relative lack of stability in the quality of the product can have repercussions on its organoleptic value as well as on its microbiological quality. Despite this lack of stability, fermented foods contain both nutritious and non-nutritious compounds that have the potential to modulate specific body functions that are responsible for the well-being and health of the consumer [7]. This fermentation is the consequence of the metabolic activity of the microorganisms present on the fruits, the water, the material used in the preparation and the production environment. Studies carried out on the microbiological characterization of fermented peppers have shown that the microorganisms colonizing this food are bacteria and yeast [5] [8] [9]. The majority of bacteria identified belong to the phyla Firmicutes and Proteobacteria. These Phyla contain bacteria with metabolic capacities that are very useful in biotechnology. Among these bacteria, one distinguishes, among others, Lactobacillus, Pediococcus, Weissella, Leuconostoc and Bacillus [10]. The presence of its bacteria is due to their metabolic capacity. Indeed, Bacilus are capable of secreting enzymes such as cellulases, xylanases and $\beta$-glucosidases [11]. With regard to bacteria of the genus Lactobacillus, it has been shown that they produce proteases, amylases, phytases, ureases, $\beta$-Glucosidases and are capable of reducing serum cholesterol levels and of producing inhibitory substances [12] [13] [14]. Thus, knowledge of the biodiversity of fermented pepper is of great interest.

In Congo Brazzaville, fermented foods play an important role in the daily life and diet of the populations. Cereals, fruits, vegetables, tubers and fish are the various raw materials used for the production of these fermented foods [6] [15] [16] [17]. Among the fermented foods, there is Pilipili or fermented pepper. Few studies have been carried out on this food. In the review by [15] chili has been cited as a fermented food from Congo. [5] had characterized the bacteria iso- 
lated from fermented peppers collected in Pointe Noire and Brazzaville. These authors identified the following bacteria species: Bacillus marisflavi, Bacillus pseudomycoides, Bacillus pumilus, Bacillus megaterium and Paenibacillus sp. However, isolation on specific media and identification of pure strains after PCR amplification of the $16 \mathrm{~S}$ rRNA gene in these authors' study cannot allow a complete study of diversity. According to [18], Culture-dependent methods only identify $1 \%$ of microorganisms present in a medium hence the use of high throughput sequencing techniques. Thus, the objective of this study was to evaluate the taxonomic diversity of bacterial communities in 3 samples of fermented peppers of different ages collected in Brazzaville using Illumina Miseq sequencing of the $16 \mathrm{~S}$ rRNA gene. This in order to identify bacteria with biotechnological potential in fermented pepper.

\section{Materials and Methods}

\subsection{Materials}

The samples of fermented peppers used in the present study were purchased in 2 markets in the city Brazzaville (Total, Ouenze). While the 3rd sample comes from the Moukondo market, the fruit peppers were bought, crushed and put in jars for a certain time of fermentation (Table 1).

\subsection{Methods}

\subsubsection{Extraction and Quantification of DNA from Bacterial Communities}

The sample preparation proceeded as follows: $250 \mathrm{mg}$ of the sample was weighed and placed in a sterile $2 \mathrm{ml}$ centrifuge tube containing $1 \mathrm{ml}$ of $70 \%$ ethanol. Then all was mixed by shaking and centrifuged at 10,000 rpm for 3 minutes at room temperature. The pellet was taken up in a solution of PBS mixed by stirring and then centrifuged again at 10,000 rpm for 3 minutes at room temperature. After discarding the supernatant, the tubes were inverted on absorbent paper for 1 $\mathrm{min}$. The tubes containing the pellet were therefore placed in an oven at $55^{\circ} \mathrm{C}$ for 10 min to completely volatilize the residual alcohol. Genomic DNA of the whole bacterial community was extracted using the OMEGA E.Z.N.ATM Mag-Bind Soil DNA Kit according to the manufacturer's instructions (Sangon Biotech, Shanghai, China).

Table 1. Origin of the different samples of peppers.

\begin{tabular}{|c|c|c|c|c|}
\hline Samples & $\begin{array}{l}\text { Packaging } \\
\text { mode }\end{array}$ & $\begin{array}{l}\text { Sample } \\
\text { Code }\end{array}$ & Origin & $\begin{array}{c}\text { Time fermentation } \\
\text { (days) }\end{array}$ \\
\hline Fermented pepper & Jar & EB1 & Total Market (Bacongo district) & 180 \\
\hline Fermented pepper & Jar & EB2 & Ouenze Market (Ouenze district) & 90 \\
\hline Fruit of pepper & Jar & EB3 & Moukondo Market (Moungali district) & 10 \\
\hline
\end{tabular}

EB1: Sample of Total market Brazzaville1; EB2: Sample of Ouenze market Brazzaville2; EB3: Sample of Moukondo market Brazzaville3. 


\subsubsection{PCR Amplification and Sequencing}

The Qubit2.0 DNA Detection Kit was used to determine the amount of genomic DNA added to the PCR reaction mix. Two universal primers 314F

(5'-CCCTACACGACGCCTCTTCCGATCTG (barcode)

CCTACGGGNGGCWGCAG-3') and 805R

(5'-ACTGGAGTTCCTTGGCACCCGAGAATTCCAGACTACHVGGGTATC

TAATCC-3') in which the barcode was a six-base sequence unique to each sample (CGGCAC, AGACTG and TTAATT), were used in PCR to amplify the V3-V4 region of the bacteria 16S rRNA gene. The following PCR conditions were used: an initial denaturation at $94^{\circ} \mathrm{C}$ for 3 minutes, 5 cycles of denaturation at $94^{\circ} \mathrm{C}$ for 30 seconds, hybridization at $45^{\circ} \mathrm{C}$ for 20 seconds, and elongation at $65^{\circ} \mathrm{C}$ for 30 seconds, 20 cycles of denaturation at $94^{\circ} \mathrm{C}$ for 20 seconds, hybridization at $55^{\circ} \mathrm{C}$ for 20 seconds and elongation at $72^{\circ} \mathrm{C}$ for 30 seconds, and final elongation at $72^{\circ} \mathrm{C}$ for $5 \mathrm{~min}$ then $10^{\circ} \mathrm{C}$. The Qubit2.0 DNA Detection Kit was used to accurately quantify the recovered DNA. The PCR products were separated by electrophoresis on $2 \%$ agarose gel and then visualized using the gel imaging system (Q32866, invitrogen). The sequencing was carried out on the Illumina MiseqTM platform at Sangon Biotech laboratory (Shanghai China).

\subsection{Data Processing}

The sequences obtained by Illumina Miseq sequencing were processed in 2 steps. The first step was to remove low quality sequences by removing barcodes, sequences of length less than $200 \mathrm{bp}$ or of average score less than 20, and the primers. This step was carried out with Cutadapt 1.2.1, Pear 0.9.6 [19], and Prinseq 0.20.4 software [20]. The second step: Chimeric sequences were detected and removed using UCHIME 4.2.40 software [21]. Afterward, OTUs defined by a 97\% similarity were selected using Usearch 5.2.236 [22]. OTUs have been grouped into different taxonomic levels in the database.

\subsection{Statistical Analyzes}

The a diversity indices (Shannon, Ace, Coverage, Chao 1, Simpson) were determined using Qiime 1.8.0 [23] and Mothur 1.30.1 [24] software. The rarefaction curves, the Venn diagram and the hierarchical classification were performed using software R.3.2 [25]. Canoco (Canonical Community ordination, version 4.5) [26] software was used for Principal Component Analysis (PCA) of dominant genera. The Excel 2013 spreadsheet was used to plot bar charts representing relative abundances at phylum and class level. At the end, a thermal diagram representing the dominant genera was produced in the statistical environment $\mathrm{R}$.

\section{Results}

\subsection{Phylogenetic Analysis and Taxonomic Richness}

Table 2 shows that the number of raw sequences obtained after sequencing with 
Illumina is $40,534,58,231$ and 31,684 for EB1, EB2 and EB3, respectively. The average length of these sequences is between 416.05 and $429.33 \mathrm{bp}$. After the quality control, the number of sequences decreased from 11,970, 51,790 and 34,132 for EB3, EB2 and EB1, respectively.

The rarefaction curve (Figure 1) shows saturation illustrated by a plateau indicating that the sampling effort has been reached for samples EB1 and EB2. However, for sample EB3 the rarefaction curve showed a beginning of the plateau. OTUs' number of in the samples was highest in EB3 (441.67), followed by EB2 (239.24) and EB1 (163.14) as revealed by the Ace estimator. The specific richness estimated by Chao1 was 157.98, 220.15 and 414.01 in EB1, EB2 and EB3, respectively. For the Shannon index, the value was higher in EB3 (2.47), followed by EB2 (2.09) and then EB1 (1.62). Finally, the values of the Simpson index were $0.40,0.24$ and 0.29 for EB1, EB2 and EB3, respectively.

\subsection{Taxonomic Diversity of the Bacterial Community}

Table 3 shows the distribution of OTUs at different taxonomic levels. All OTUs belong to the domain of Bacteria. These OTUs are divided into 21 Phyla, 36 Classes, 58 Orders, 100 Families and 171 genera. Sample EB1 contains fewer taxa in each taxonomic level, 5 Phyla, 8 classes, 12 orders, 19 families and 25 genera. Follow-up of sample EB2 which contains 8 phyla, 15 classes, 25 orders, 47 families and 80 genera. Finally, EB3 contains more taxa in each taxonomic level than the first two samples (Table 3 ). The difference in the number of taxa in the 3 samples is significant $(\mathrm{P}<0.045)$.

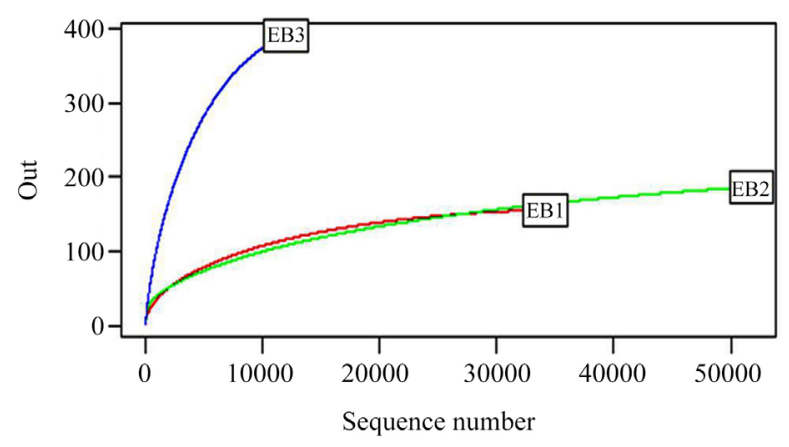

Figure 1. Rarefaction curves derived from the observed OTU number and species accumulation curves.

Table 2. Operational taxonomic units (OTU) and estimate of species richness.

\begin{tabular}{cccccccccc}
\hline $\begin{array}{c}\text { Sample } \\
\text { ID }\end{array}$ & $\begin{array}{c}\text { Seq } \\
\text { num }\end{array}$ & $\begin{array}{c}\text { Mean } \\
\text { len. }\end{array}$ & Seq num & $\begin{array}{c}\text { OTU } \\
\text { num }\end{array}$ & $\begin{array}{c}\text { Shannon } \\
\text { Index }\end{array}$ & $\begin{array}{c}\text { Ace } \\
\text { Index }\end{array}$ & $\begin{array}{c}\text { Chao1 } \\
\text { Index }\end{array}$ & Coverage & Simpson \\
\hline EB1 & 40,534 & 429.33 & 34,132 & 156 & 1.62 & 163.14 & 157.98 & 1.00 & 0.40 \\
EB2 & 58,231 & 416.05 & 51,790 & 187 & 2.09 & 239.24 & 220.15 & 1.00 & 0.24 \\
EB3 & 31,684 & 417.11 & 11,970 & 392 & 2.47 & 441.67 & 441.01 & 0.99 & 0.29 \\
\hline
\end{tabular}

EB1: Sample of Total market Brazzaville1; EB2: Sample of Ouenze market Brazzaville2; EB3: Sample of Moukondo market Brazzaville3; $\left(^{*}\right)$ Number of sequences before treatment; Seq: sequences; num: number ; len: length. 
Table 3. Distribution of OTUs at different levels.

\begin{tabular}{ccccccc}
\hline Samples & Domain & Phylum & Class & Order & Family & Genus \\
\hline EB1 & 1 & 5 & 8 & 12 & 19 & 25 \\
EB2 & 1 & 8 & 15 & 25 & 47 & 80 \\
EB3 & 1 & 19 & 32 & 52 & 86 & 135 \\
\hline
\end{tabular}

EB1: Sample of Total market Brazzaville1; EB2: Sample of Ouenze market Brazzaville2; EB3: Sample of Moukondo market Brazzaville3.

Table 4 shows the distribution of the main OTUs in the different taxonomic levels. Firmicutes (99.51\%) were the main dominant phylum in sample EB1, while in EB2, Firmicutes (82.39\%) Proteobacteria (14.04\%) and Actinobacteria (3.52\%) were dominant. In sample EB3, Firmicutes and Proteobacteria were the most representative with relative abundances of $87.87 \%$ and $9.73 \%$, respectively. The main dominant classes were Bacilli (99.50\% EB1, 42.29\% EB2 and 85.32\% EB3), Alphaproteobacteria (10.37\% EB2, 9.73\% EB3) and Gammaproteobacteria (2.54\% EB2, 2.79\% EB3), while the Clostridia class was only found in samples EB2 and EB3 with $40.1 \%$ and $1.61 \%$ relative abundance respectively. On the other hand, Actinobacteria were only present in EB2 with a relative abundance of $3.52 \%$. The most representative order was that of Lactobacillales present in the three samples with $99.38 \%$ in EB1, 39.82\% in EB2 and $84.87 \%$ in EB3. Clostridiales although absent in EB1 constitute the second dominant order with $42.29 \%$ in EB2. The main families were made up of Lactobacillaceae with $99.38 \%$ in EB1, 39.75\% in EB2 and $17.27 \%$ in EB3 followed by Leuconostocaceae $66.27 \%$ in EB3, Clostridiaceae 42.21\%, Acetobacteriaceae $8.83 \%$ and Bifidobacteriaceae $3.49 \%$ in EB2. The dominant genera were represented by Lactobacillus in the three samples $99.38 \%$ in EB1, 39.75\% in EB2 and $17.17 \%$ in EB3. This genus was followed by Fructobacillus $57.65 \%$ in EB3 and Clostridium sensu stricto in EB2 with $42.21 \%$.

The Venn diagram (Figure 2) indicates that 19 OTUs was common to the 3 samples, while 23 OTUs was common to EB1 and EB2, 41 OTUs common to EB2 and EB3, 3 was common to EB1 and EB3. However, the OTUs specific to EB1, EB2 and EB3 were numbered 111, 104 and 329, respectively.

\subsection{Structural Analysis of Bacterial Communities}

The structures of the bacterial communities of the 3 samples were also compared by a hierarchical classification (Figure 3). Analysis of the dendrogram shows 2 classes: one class formed by the cluster containing samples EB1 and EB2 and another formed by sample EB3.

Principal component analysis (PCA) showed that axes 1 and 2 explain all of the variation in dominant genera in the 3 samples, i.e. $100 \%$ of the total variation (Figure 4). Axis 1 represents $56.3 \%$ and axis $243.7 \%$ of the total variance. Regarding axis 1, the genera Lactobacillus, Rhizobium, Ochrobactrum, Aescorvia, Kluyvera, Clostridium sensu_stricto, Acetobacter, Burkholderia and Unclassified are positively correlated against the other genera are negatively correlated. With 
respect to axis 2, the genera Lactobacillus, Rhizobium, Ochrobactrum, Aeriscorvia and Klebsiella are positively correlated and the rest of the genera have a negative correlation. These results also indicate that the 3 samples are clearly different.

Table 4. Distribution of the main OTUs at different levels (taxa).

\begin{tabular}{|c|c|c|c|c|}
\hline Level & OTU ID & EB1 (\%) & EB2 (\%) & EB3 (\%) \\
\hline \multirow{3}{*}{ Phylum } & Firmicutes & 99.51 & 82.39 & 87.87 \\
\hline & Proteobacteria & - & 14.04 & 9.73 \\
\hline & Actinobacteria & - & 3.52 & - \\
\hline \multirow{6}{*}{ Class } & Bacilli & 99.50 & 42.29 & 85.32 \\
\hline & Clostridia & - & 40.10 & 1.61 \\
\hline & Alphaproteobacteria & - & 10.37 & 9.73 \\
\hline & Gammaproteobacteria & - & 2.54 & 2.79 \\
\hline & Betaproteobacteria & - & 1.12 & 1.12 \\
\hline & Actinobacteria-class & - & 3.52 & - \\
\hline \multirow{8}{*}{ Order } & Lactobacillales & 99.38 & 39.82 & 84.87 \\
\hline & Clostridiales & - & 42.29 & 1.16 \\
\hline & Rhizobiales & - & 1.44 & - \\
\hline & Enterocateriales & - & 1.45 & 2.10 \\
\hline & Burkholderiales & - & 1.12 & - \\
\hline & Rhodispirillales & - & 8.83 & 5.11 \\
\hline & Xanthomonodales & - & 1.01 & - \\
\hline & Bifidobacterales & - & 3.49 & - \\
\hline \multirow{8}{*}{ Family } & Lactobacillaceae & 99.38 & 39.75 & 17.27 \\
\hline & Leuconostocaceae & - & - & 66.27 \\
\hline & Streptococcaceae & - & - & 1.19 \\
\hline & Clostridiaceae-1 & - & 42.21 & - \\
\hline & Enterobacteriaceae & - & 1.45 & 2.10 \\
\hline & Acetobacteriaceae & - & 8.83 & 5.11 \\
\hline & Xanthomonadaceae & - & 1.01 & - \\
\hline & Bifidobacteriaceae & - & 3.49 & - \\
\hline \multirow{9}{*}{ Genus } & Lactobacillus & 99.38 & 39.75 & 17.17 \\
\hline & Leuconostoc & - & - & 5.96 \\
\hline & Weissella & - & - & 2.66 \\
\hline & Fructobacillus & - & - & 57.65 \\
\hline & Clostridium-sensu-stricto & - & 42.21 & - \\
\hline & Lactococcus & - & - & 1.14 \\
\hline & Acetobacter & - & 8.79 & 4.92 \\
\hline & Stenotrophomonas & - & 1.00 & - \\
\hline & Aeriscodovia & - & 3.37 & - \\
\hline
\end{tabular}




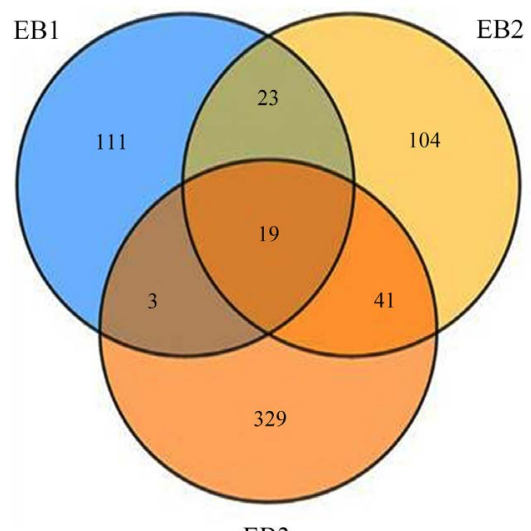

EB3

Figure 2. Venn analysis of unique and shared OTUs of different sample.

Bray TREE PLOT

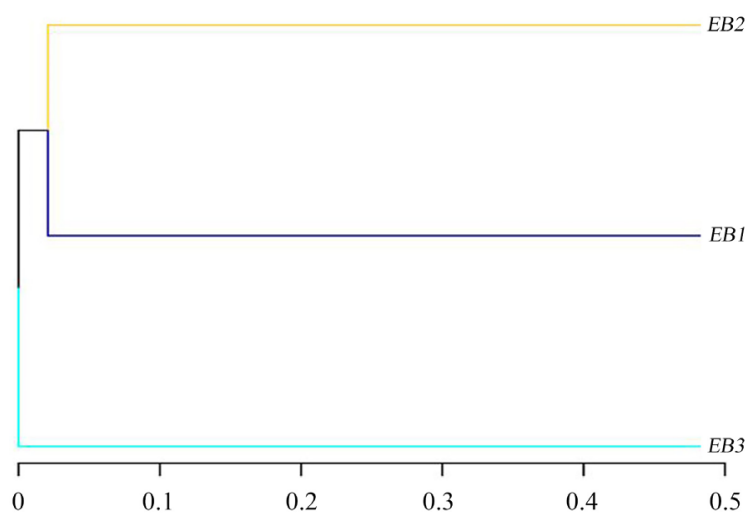

Figure 3. Hierarchical cluster analysis dendrogram based on the OTUs of 3 fermented Pepper products.

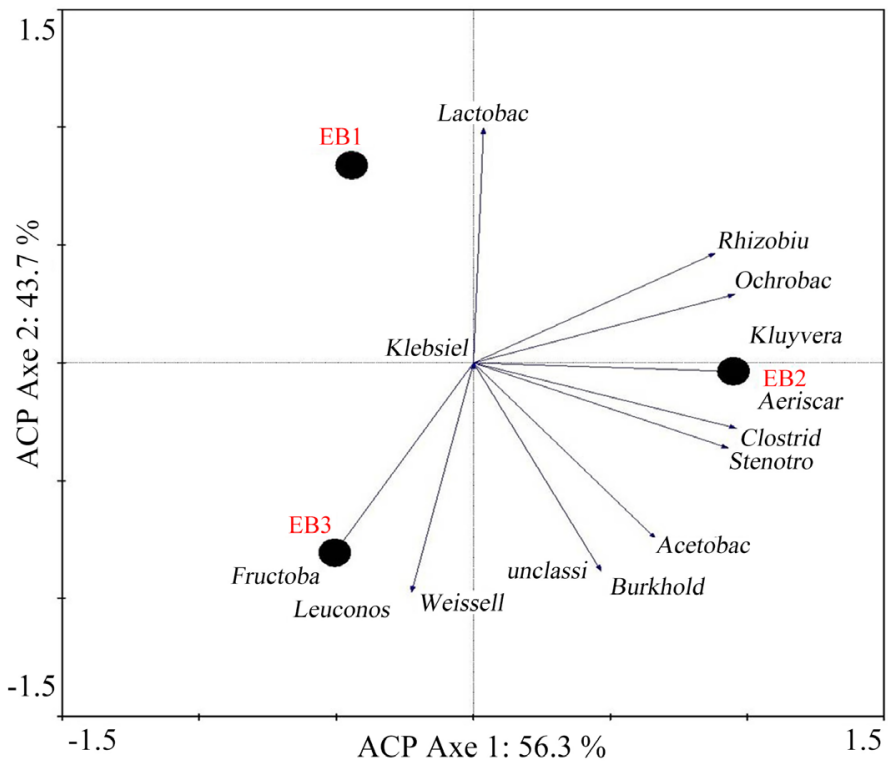

Figure 4. Principal component analysis for the sample based on genus. 


\subsection{Relative Abundance at the Level of the Phylum}

Figure 5 shows the relative abundances of all phyla in the three samples. Twenty-one Phyla were identified in all samples including 5 for EB1, 8 for EB2 and 19 for EB3. In sample EB1, Firmicutes were the most dominant. While in EB2, Firmicutes were the most dominant Phylum followed by Proteobacteria and Actinobacteria. Finally, in EB3, Firmicutes and Proteobacteria were more abundant. Figure 6 shows the different classes of the 3 samples of fermented pepper. The most represented class is that of Bacilli with 99.50\% in EB1 and 85.32\% in EB3. In samples EB2 the most representative classes were Clostridia (42.29\%.), Bacilli (40.10\%), Alphaproteobacteria (10.37\%), Actinobacteria (3.52\%), Gammaproteobacteria (2.54\%) and Betaproteobacteria (1.12\%). against in EB3 Bacili (85.33\%), Alphaproteobacteria (5.62\%), Gammaprteobacteria (2.79\%), Clostridia (1.61\%) and Betaproteobacteria (1.12\%).

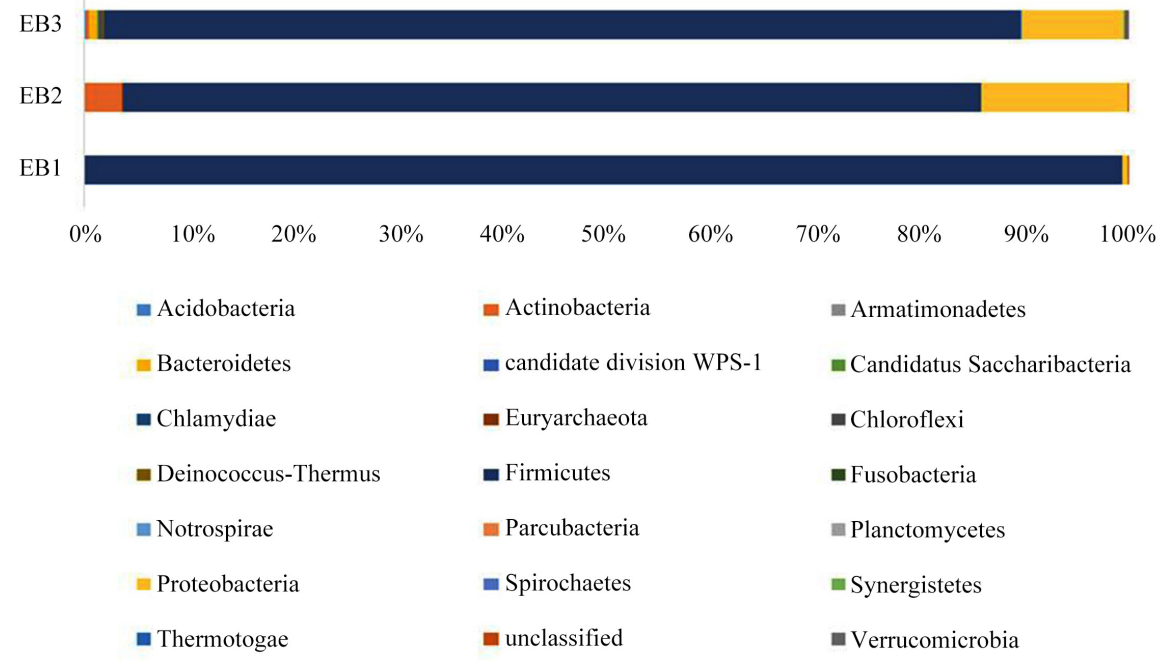

Figure 5. Relative abundance of Phylum (Phylum level).

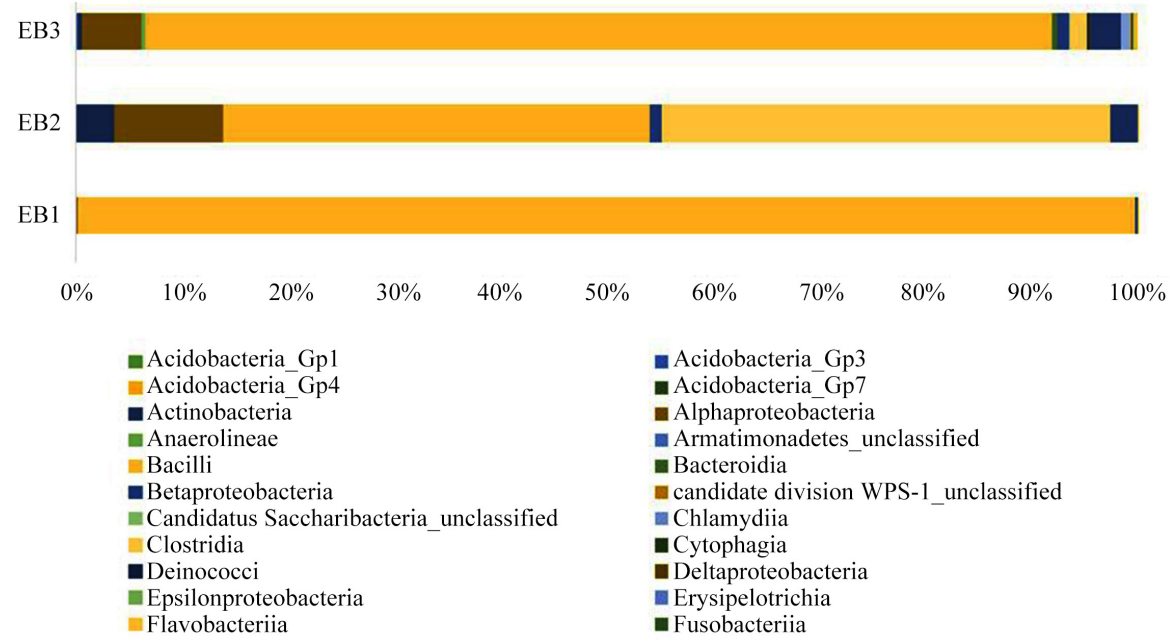

Figure 6. Relative abundance of Classes (Class level). 
In the EB1 sample Lactocillus was the only dominant genus with a relative abundance of $99.37 \%$. In contrast in EB2, 4 genera were dominant, Clostridium sensu stricto (42.21\%), Lactobacillus (39.74\%), Acetobacter (8.79), Aeriscardovia (3.36\%) and Stenotrophomonas (1\%). Finally, in EB3, 6 genera were dominant in addition to an unclassified genus (2.33\%). Fructobacillus (57.65\%), Lactobacillus (17.16\%), Leuconostoc (5.95\%), Acetobacter (4.92\%), Weissella (2.65\%), Lactococcus (1.14\%) (Figure 7).

\subsection{Abundant and Rare Microorganisms}

The heat diagram shows the abundant and rare genera in samples EB1, EB2 and EB3 (Figure 8). Lactobacillus was very abundant in EB1 but less in EB2 and EB3. Against the genus Clostridium sensu-stricto was abundant in EB2 and rare in EB1 and EB3. Fructobacillus was only abundant in EB3 and rare in the other 2 samples. The genus Bacillus was rare in all samples.

\section{Discussion}

Pepper (Capsicum sp.), Very well known in the world, is a fruit used as a condiment or spice. In the Republic of Congo, it is also consumed after fermentation. The latter is carried out by microorganisms which play an essential role [27]. Studies carried out on the diversity of microorganisms in fermented foods increasingly use high throughput sequencing methods [28] [29]. However, in Congo, studies on the microbial diversity of fermented foods have focused on cultivable strains [6] [16]. [5], for example, showed the presence of Bacillus marisflavi, B. pseudomycoides, B. pumilus, B. megateriumwere and Paenibacillus sp

Distribution Barplot



EB1

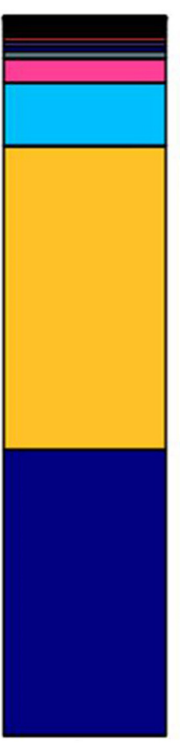

EB2

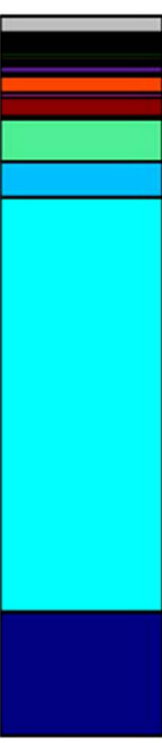

EB3

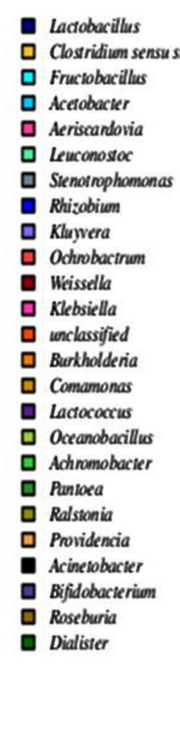
M Mergandla - Faecalibacterium - Bacillus

EscherichiaShigella

- Sphingomonas

Sphingomones

Solibacillus

Lysinibacillus

Meiothermus

Natranaenvirga

口 Pseudomonas

Nitrosomonas

․ Serratia

a Bactervides

- Phenylobacterien

口 Collinsella

a Aminobacteriven

- Puncoccus

Simplicispira

ㄴ.mplicispira

Geobacter

口 Pediococcus

Leptolinea

a Alstipes

$\square$ other

Figure 7. Bacterial communities of the 3 fermented pepper products genus level. 


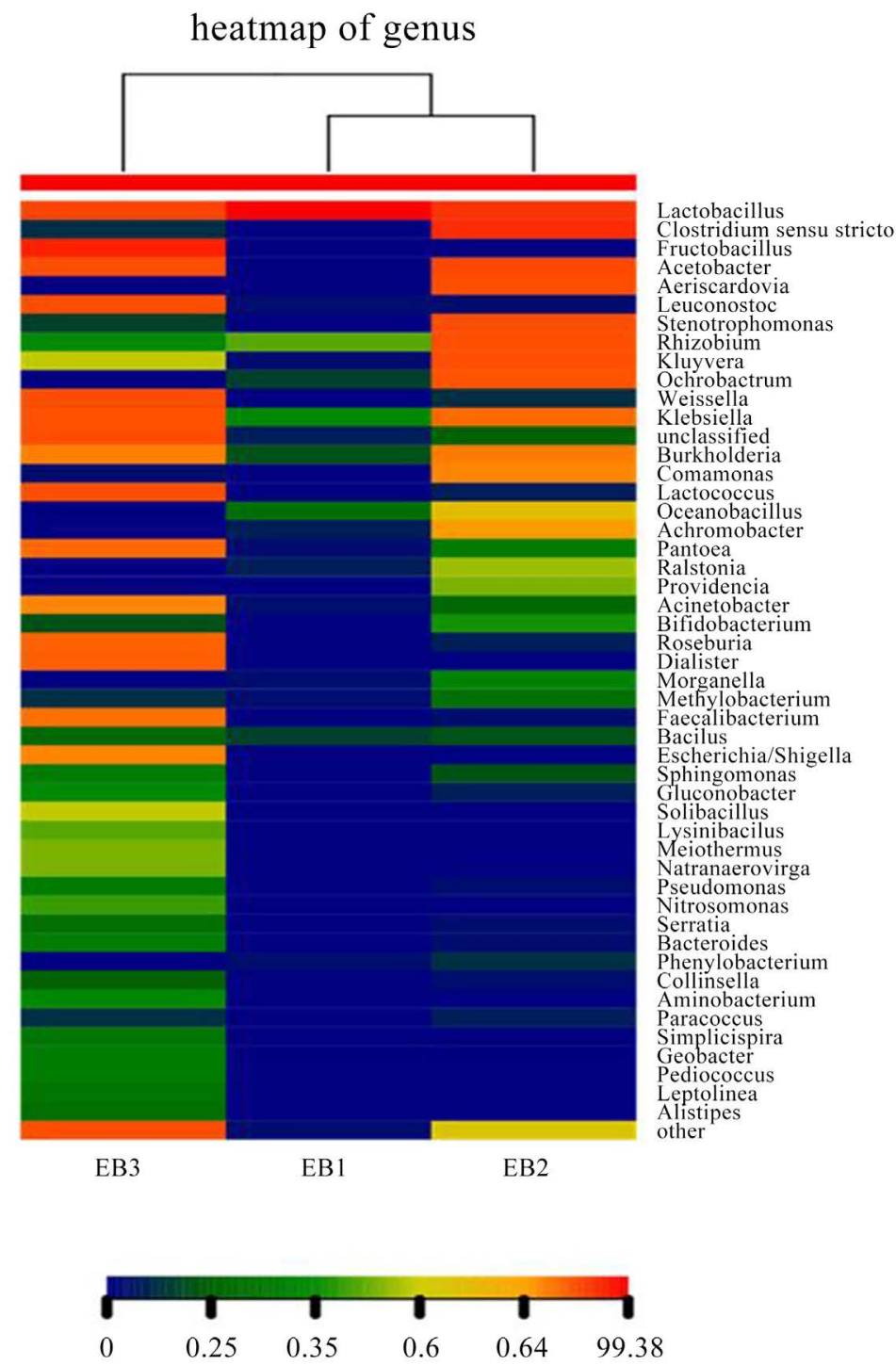

Figure 8. Heatmap showing the bacterial distribution of the top 50 abundant genera among the 3 fermented vegetable products.

in fermented chilli pepper using culture-dependent methods. In the present study, the bacterial diversity of three samples of fermented pepper with different fermentation times was investigated by Illumina Miseq by targeting the $16 \mathrm{~S}$ rRNA gene. A number of 97,892 sequences (reads) was obtained in the 3 samples and grouped into 735 OTUs with a similarity of $97 \%$. All OTUs belong to the domain of Bacteria and have been classified into 21 phyla, 36 classes, 58 orders, 100 families and 171 genera. The richness estimators of Chao, ACE and the Shannon index were higher in EB3 and EB2, showing a large variation in bacterial richness in these samples. However, the Simpson index was higher in EB1 indicating low bacterial diversity in this sample. These results are justified by the fact that EB3 is the youngest sample with a short fermentation time compared to EB1 is the oldest. These results agree with the studies of [30] [31]. These authors have shown that the higher the Shannon index and the lower the Simpson's in- 
dex, the diversity is high. It is interesting to note that 19 OTUs were common to the 3 samples. This explains why peppers at different fermentation times and from different places of production have bacterial communities in common. These include, among others, Firmicutes and Proteobacteria at the phylum level, Bacili and Alphaproteobacteria at the class level and Lactobacillus at the genus level. [27] also obtained a common microbial community nucleus from 7 samples of fermented foods from 7 different localities. This nucleus was composed of 25 OTUs including Firmicutes, Proteobacteria, Actinobacteria and Bacteroides at the phylum level and Bacilli at the class level. In the study by [30], 10 common OTUs were obtained on 2 fermented foods from different localities. These Units are composed, among other things, of Firmicutes at the phylum level and Lactobacillus at the genus level. The presence of this core of bacteria common to all samples of fermented foods is probably due to the fact that these bacteria are involved in the fermentation process.

Regarding the composition of the bacterial community, Firmicutes and Proteobacteria were the most dominant phyla in all 3 fermented pepper samples. These results agree with previous studies [27] [32] [33] [34] which also found the same dominant phyla. The presence of these dominant phyla in fermented foods is due to the fact that they contain bacteria involved in fermentation processes such as lactic acid bacteria. In addition to these phyla, Actinobacteria, Acidobacteria, Bacterioidetes, Chloroflexi, Deinococcus-thermus were found in low percentages from sample to sample. These phyla have been found in other fermented foods by other authors [33] [35]. A certain number of sequences could not be affiliated with a phylum. These sequences are qualified as unclassified. [36] [37] also found unclassified sequences at the Phylum level. These sequences may correspond to sequences that do not exist in the databases or constitute new strains. Bacilli, Clostridia and Alphaproteobacteria were the dominant classes from sample to sample. These results are similar with the study of [38] who also obtained Bacilli and Clostridia on fermented baiju seeds. The dominance of these classes is due to the fact that they contain bacteria capable of sporulating and growing in an acidic environment. These properties are very important to withstand fermentation conditions.

At the genus level, Lactobacillus, Clostridium sensu-stricto and Fructobacillus were dominant in samples EB1, EB2 and EB3, respectively. These results are close to previous studies which have shown that the dominant genera in fermented foods differ depending on the place of production. In the study of [27] focusing on fermented vegetables in China, Lactobacillus was dominant in fermented mustards from Yuyao locality in Zhejiang and Pseudomonas in Tongxiang locality in Zhejiang. While, Chromohalobacter was dominant in Fermented Radish from Xiaoshan in Zhejiang and Bacillus in Fermented Pepper from Meishan in Sichuan. [32] also found that in all fermented cabbage samples, Lactobacillus were more dominant. However, in samples from Paocai, in addition to Lactobacillus, the genera Serratia and Stenotrophomonas were dominant. Similar results were found in traditional sourdoughs by [39]. Indeed, in the 
study of these authors, Lactobacillus was the dominant genus in sourdough samples from northern and southern China. In contrast, Pediococcus was dominant in the eastern sample. These differences can be explained by the fact that the raw material comes from different localities, therefore probably does not carry the same microorganisms, then the production environment is not the same [32]. Furthermore, the presence of these bacteria in fermented peppers can be justified by their ability to use the substrates present in the medium. The bacterial genera belonging to the lactic acid bacteria group are responsible for the production of metabolites (enzymes and vitamins) allowing the improvement of the quality of food, the bioconservation and the inhibition of pathogens [16] [40]. In addition, certain genera identified in this study have never been identified from fermented chilli peppers from the Congo. These include Fructobacillus, Kleyvera, Aeriscodovia, Stenotrophomonas, Ochrobactrum and Oceanobacillus, among others. This is because the Illumina Miseq method used in this work is more potent than the cultivation methods used in Congo. However, some of these genera have been identified in other fermented foods. The study of [41] revealed the presence of the genus Fructobacillus in fermented cocoa. [27] also isolated the genus Stenotrophomonas in fermented mourtades. A few unclassified sequences could not be attributed to a genus. These results agree with the studies of [42] which also found unknown genera sequences.

Principal component analysis based on the numbers of dominant genera revealed that the 3 samples are markedly different. The 3-month EB2 sample from the Ouenze market contains more dominant genres followed by the EB3 sample. These results agree with those of [35] [42]. These authors pointed out that the structure of microbial diversity in fermented foods is influenced by the place of production and the duration of fermentation. [42] showed that the diversity was higher at the start of fermentation than at the end.

\section{Conclusion}

The objective of this work was to study bacterial diversity in 3 fermented foods using the Illumina Miseq technique targeting the 16S rRNA gene. The results showed that samples EB3 and EB2 were more diverse than EB1. Firmicutes, Proteobacteria and Actinobacteria were the dominant phyla in all 3 samples. At the gender level, Lactobacillus was dominant in the EB1 sample, Clostridim sensu-stricto in EB2 and Fructobacillus in EB3. In addition to these dominant genera, other genera were first identified in a fermented food in Congo including Fructobacillus and Aeriscodovia. Therefore, the firmness pepper can be a source for the isolation of bacteria which can be used in biotechnological processes.

\section{Acknowledgements}

We would like to thank Dr. Armel IBALA ZAMBA (IRSEN/UMNG) for insightful comments on an earlier version of the manuscript and for introducing AELB to the use of the Canoco software. 


\section{Conflicts of Interest}

The authors declare no conflicts of interest regarding the publication of this paper.

\section{References}

[1] Kouassi kouassi, C. and Koffi-nevry, R. (2012) Evaluation de la connaissance et utilisation des variétés de piment (capsicum) cultivées en côte d'ivoire. International Journal of Biological and Chemical Science, 6, 175-185. https://doi.org/10.4314/ijbcs.v6i1.16

[2] Dagnoko, S., Yaro-Diarisso, N., Sanogo, P.N., Adetula, O., Dolo-Nantoumé, A., Gamby-Touré, K., Traoré-Théra, A., Katilé, S. and Diallo-Ba, D. (2013) Overview of Pepper (Capsicum spp.) Breeding in West Africa. African Journal of Agricultural Research, 8, 1108-1114. https://doi.org/10.5897/AJAR2012.1758

[3] Kouassi kouassi, C., Koffi-nevry, R., Yao, L.G., Nanga, Z.Y., Koussémon, M., Kablan, T. and Kouassi, K.A. (2012) Profiles of Bioactive Compounds of Some Pepper Fruit (Capsicum L.) Varieties Grown in Côte D'ivoire. Innovative Romanian Food Biotechnology, 11, 23-31.

[4] Tano, K., Koffi-Nevry, R., Koussémon, M. and Oulé, M.K. (2008) The Effects of Different Storage Temperatures on the Quality of Fresh Bell Pepper (Capsicum annum L.). Agricultural Journal, 3, 157-162.

[5] Mokemiabeka, N.S., Kayath, C.A., Nguimbi, E., Lébonguy, A.A., Eboungabeka, A.G.M., Mendosa, D.R., Kéléké, S., Kobawila, S.C. and Botteaux, A. (2016) Microbiological and Biochemical Assessment of Crushed Red Pepper from Capsicum frutescens Preserved in Jars and Manufactured in Local Markets in Republic of Congo. International Journal of Biotechnology Research, 4, 1-10.

[6] Louémbé, D., Kobawila, S.C., Bouanga-Kalou, G. and Kéléké, S. (2003) Etude microbiologique des feuillesfermentées de manioc: Ntobambodi. Tropicultura, 21, 106-111.

[7] Tamang, J.P., Shin, D.H., Jung, S.J. and Chae, S.W. (2016) Functional Properties of Microorganisms in Fermented Foods. Frontiers in Microbiology, 7, 578. https://doi.org/10.3389/fmicb.2016.00578

[8] Garbowska, M., Berthold-Pluta, A. and Stasiak-Rozanska, L. (2015) Microbiological Quality of Selected Spices and Herbs Including the Presence of Cronobacter spp. Food Microbiology, 49, 1-5. https://doi.org/10.1016/j.fm.2015.01.004

[9] Vegas, C., Zavaleta, A.I. and Zarzoso, B. (2018) Optimization of Fermentation Process Conditions for Chili Pepper (Capsicum frutescens) Fruit Using Response Surface Methodology. Agronomia Colombiana, 36, 89-97. https://doi.org/10.15446/agron.colomb.v36n1.69164

[10] Nuraida, L. (2015) A Review: Health Promoting Lactic Acid Bacteria in Traditional Indonesian Fermented Foods. Food Science and Human Wellness, 4, 47-55. https://doi.org/10.1016/j.fshw.2015.06.001

[11] Moutou-Tchitoula, D.P., Nguimbi, E., Giusti-Miller, S., Mora, P., Kobawila, S.C. and Miambi, E. (2018) Assessment of Dominant Bacterial Strains Isolated from Ntoba Mbodi, an Indigenous African Alkaline-Fermented Food, and Their Potential Enzyme Activities. African Journal of Microbiology Research, 12, 779-787. https://doi.org/10.5897/AJMR2018.8875

[12] Anila, K., Kunzes, A. and Bhalla, T.C. (2016) In Vitro Cholesterol Assimilation and Functional Enzymatic Activities of Putative Probiotic Lactobacillus sp. İsolated 
from Fermented Foods/Beverages of North West India. Journal of Nutrition and Food Sciences, 6, 2. https://doi.org/10.4172/2155-9600.1000467

[13] Iranmanesh, M., Ezzatpanah, H. and Mojgani, N. (2014) Antibacterial Activity and Cholesterol Assimilation of Lactic Acid Bacteria Isolated from Traditional Iranian Dairy Products. LWT-Food Science and Technology, 58, 355-359. https://doi.org/10.1016/j.lwt.2013.10.005

[14] Dortu, C. and Thonart, P. (2009) Les bactéries lactiques: Caractéristiques et intérêts pour la bioconservation des produits alimentaires. Biotechnologie Agronomie Société et Environnement, 13, 143-154.

[15] Kayath, C.A., Nguimbi, E., Goma-Tchimbakala, J., Mamonékéné, V., Lebonguy, A.A. and Ahombo, G. (2016) Towards the Understanding of Fermented Food Biotechnology in Congo Brazzaville. Advance Journal of Food Science and Technology, 12, 593-602. https://doi.org/10.19026/ajfst.12.3317

[16] Louémbé, D., Keléké, S., Kobawila, S.C. and Nzounzi, J.P. (2003) Bactéries lactiques de la pâte fermentée de maïs au Congo. Tropicultura, 21, 3-9.

[17] Miambi, E., Guyot, J.P. and Ampe, F. (2003) Identification, Isolation and Quantification of Representative Bacteria from Fermented Cassava Dough Using an Integrated Approach of Culture Dependent and Culture-Independent Methods. International Journal of Food Microbiology, 82, 111-120. https://doi.org/10.1016/S0168-1605(02)00256-8

[18] Hugenholtz, P. (2002) Exploring Prokaryotic Diversity in the Genomic Era. Genome Biology, 3, REVIEWS0003. https://doi.org/10.1186/gb-2002-3-2-reviews0003

[19] Zhang, J., Kobert, K., Flouri, T. and Stamatakis, A. (2014) PEAR a Fast and Accurate Illumina Paired-End reAd mergeR. Bioinformatics, 30, 614-620. https://doi.org/10.1093/bioinformatics/btt593

[20] Schmieder, R. and Edwards, R. (2011) Quality Control and Preprocessing of Metagenomic Datasets. Bioinformatics, 27, 863-864. https://doi.org/10.1093/bioinformatics/btr026

[21] Edgar, R.C., Haas, B.J., Clemente, J.C., Quince, C. and Knight, R. (2011) UCHIME Improves Sensitivity and Speed of Chimera Detection. Bioinformatics, 27, 2194-2200. https://doi.org/10.1093/bioinformatics/btr381

[22] Edgar, R.C. (2010) Search and Clustering Orders of Magnitude Faster than BLAST. Bioinformatics, 26, 2460-2461. https://doi.org/10.1093/bioinformatics/btq461

[23] Caporaso, J.G., Kuczynski, J., Stombaugh, J., Bittinger, K., Bushman, F.D., Costello, E.K., Fierer, N., Peña, A.G., Goodrich, J.K., Gordon, J.I., Huttley, G.A., Kelley, S.T., Knights, D., Koenig, J.E., Ley, R.E., Lozupone, C.A., McDonald, D., Muegge , B.D., Pirrung, M., Reeder, J., Sevinsky, J.R., Turnbaugh, P.J., Walters, W.A., Widmann, J., Yatsunenko, T., Zaneveld, J. and Knight, R. (2010) QIIME Allows Analysis of High-Throughput Community Sequencing Data. Nature Methods, 7, 335-336. https://doi.org/10.1038/nmeth.f.303

[24] Schloss, P.D., Westcott, S.L., Ryabin, T., Hall, J.R., Hartmann, M., Hollister, E.B., Lasniewski, R.A., Oakley, B.B., Park, D.H., Robinson, C.J., Sahl, J.W., Stres, B., Talliger, G.G., Van Horn, D.J. and Weber, C.F. (2009) Introducing Mothur: Open-Source, Platform-Independent, Community-Supported Software for Describing and Comparing Microbial Communities. Applied and Environmental Microbiology, 75, 7537-7541. https://doi.org/10.1128/AEM.01541-09

[25] Cao, J., Yang, J., Hou, Q., Xu, H., Zheng, Y., Zhang, H. and Zhang, L. (2017) Assessment of Bacterial Profiles in Aged, Home-Made Sichuan Paocai Brine with Varying Titratable Acidity by PacBio SMRT Sequencing Technology. Food Control, 
78, 14-23. https://doi.org/10.1016/j.foodcont.2017.02.006

[26] Ter Braak, C.J.F. and Smilauer, P. (2003) Canoco 4. Cambridge University Press, Cambridge, $242 \mathrm{p}$.

[27] Liu, D.Q. and Tong, C. (2017) Bacterial Community Diversity of Traditional Fermented Vegetables in China. LWT-Food Science and Technology, 86, 40-48. https://doi.org/10.1016/j.lwt.2017.07.040

[28] Zhang, J., Wang, X., Huo, D., Li, W., Hu, Q., Xu, C., Liu, S. and Li, C. (2016) Metagenomic Approach Reveals Microbial Diversity and Predictive Microbial Metabolic Pathways in Yucha, a Traditional Li Fermented Food. Scientific Reports, 6, Article No. 32524. https://doi.org/10.1038/srep32524

[29] Serra, J.L., Moura, F.G., de Melo Pereira, G.V., Soccol, C.R., Rogeza, H. and Darneta, S. (2019) Determination of the Microbial Community in Amazonian Cocoa Bean Fermentation by Illumina-Based Metagenomic Sequencing. LWT_Food Science and Technology, 106, 229-239. https://doi.org/10.1016/j.lwt.2019.02.038

[30] Li, H., Li, Z., Qu, J. and Wang, J. (2017) Bacterial Diversity in Traditional Jiaozi and Sourdough Revealed by High-Throughput Sequencing of 16S rRNA Amplicons. Food Science and Technology, 81, 319-325.

https://doi.org/10.1016/j.lwt.2017.04.007

[31] Jiménez, E., Yépez, A., Pérez-Cataluňa, A., Vásquez, E.R., Dávila, D.Z., Vignolo, G. and Aznar, R. (2018) Exploring Diversity and Biotechnological Potential of Lactic Acid Bacteria from Tocosh-Traditional Peruvian Fermented Potatoes-By High Throughput Sequencing (HTS) and Culturing. LWT-Food Science and Technology, 87, 567-574. https://doi.org/10.1016/j.lwt.2017.09.033

[32] Liu, Z., Penga, Z., Huanga, T., Xiaoa, Y., Li, J., Xie, M. and Xiong, T. (2019) Comparison of Bacterial Diversity in Traditionally Homemade Paocai and Chinese Spicy Cabbage. Food Microbiology, 83, 141-149. https://doi.org/10.1016/j.fm.2019.02.012

[33] Nam, Y.D., Yi, S.H. and Lim, S.I. (2012) Bacterial Diversity of Cheonggukjang, a Traditional Korean Fermented Food, Analyzed by Barcoded Pyrosequencing. Food Control, 28, 135-142. https://doi.org/10.1016/j.foodcont.2012.04.028

[34] Park, E.J., Chun, J., Cha, C.J., Park, W.S., Jeon, C.O. and Bae, J.W. (2012) Bacterial Community Analysis during Fermentation of Ten Representative Kinds of Kimchi with Barcoded Pyrosequencing. Food Microbiology, 30, 197-204. https://doi.org/10.1016/j.fm.2011.10.011

[35] Phewpana, A., Phuwaprisirisanb, P., Takahashic, H., Ohshimac, C., Lopetcharatd, K., Techaruvichite, P. and Keeratipibulf, S. (2020) Microbial Diversity during Processing of Thai Traditional Fermented Shrimp Paste, Determined by Next Generation Sequencing. LWT-Food Science and Technology, 122, 108-989. https://doi.org/10.1016/j.lwt.2019.108989

[36] Jung, W.Y., Jung, J.Y., Lee, H.J. and Jeon, C.O. (2016) Functional Characterization of Bacterial Communities Responsible for Fermentation of Doenjang: A Traditional Korean Fermented Soybean Paste. Frontiers in Microbiology, 7, 827. https://doi.org/10.3389/fmicb.2016.00827

[37] Wang, X., Du, H. and Xu, Y. (2017) Source Tracking of Prokaryotic Communities in Fermented Grain of Chinese Strong-Flavor Liquor. International Journal of Food Microbiology, 244, 27-35. https://doi.org/10.1016/j.ijfoodmicro.2016.12.018

[38] Chai, L.J., Lu, Z.M., Zhang, X.J., Ma, J., Xu, P.X., Qian, W., Xiao, C., Wang, S.T., Shen, C.H., Shi, J.S. and Xu, Z.H. (2019) Zooming in on Butyrate-Producing Clostridial Consortia in the Fermented Grains of Baijiu via Gene Sequence-Guided Microbial Isolation. Frontiers in Microbiology, 10, 1397. 
https://doi.org/10.3389/fmicb.2019.01397

[39] Liu, X., Zhoua, M., Jiaxina, C., Luoc, Y., Yed, F., Jiaoe, S., Huc, X., Zhang, J. and Lüa, X. (2018) Bacterial Diversity in Traditional Sourdough from Different Regions in China. LWT-Food Science and Technology, 96, 251-259.

https://doi.org/10.1016/j.lwt.2018.05.023

[40] Ennadir, J., Hassikou, R., Al Askari, G., Arahou, M., Bouazza, F., Amallah, L., Amine, S.A. and Khedid, K. (2014) Caractérisation phénotypique et génotypique des bactéries lactiques isolées des farines de blé d'origine marocaine (Phenotypic and Genotypic Characterization of Lactic Acid Bacteria Isolated from Wheat Flour from Morocco). Journal of Materials and Environmental Science, 5, 1125-1132.

[41] Snauwaert, I., Papalexandratou, Z., De Vuys, L. and Vandamme, P. (2013) Characterization of Strains of Weissella fabalis sp. nov. and Fructobacillus tropaeoli from Spontaneous Cocoa Bean Fermentations. International Journal of Systematic and Evolutionary Microbiology, 63, 1709-1716. https://doi.org/10.1099/ijs.0.040311-0

[42] Liang, H., Yin, L., Zhang, Y., Chang, C. and Zhang, W. (2018) Dynamics and Diversity of a Microbial Community during the Fermentation of Industrialized Qingcai Paocai, a Traditional Chinese Fermented Vegetable Food, as Assessed by Illumina MiSeq Sequencing, DGGE and qPCR Assay. Annals of Microbiology, 68, 111-122. https://doi.org/10.1007/s13213-017-1321-Z 